\title{
Cardiac and metabolic physiology of early larval zebrafish (Danio rerio) reflects parental swimming stamina
}

\section{Matthew Gore and Warren W. Burggren*}

Developmental Integrative Biology Cluster, Department of Biological Sciences, University of North Texas, Denton, TX, USA

\section{Edited by:}

Richard Londraville, University of Akron, USA

\section{Reviewed by:}

Brad Buckley, Portland State

University, USA

David Marcinek, University of

Washington, USA

Tim Moerland, Kent State University, USA

\section{*Correspondence.}

Warren W. Burggren, Department of Biological Sciences, University of North Texas, 1155 Union Circle \#305220, Denton, TX 76203, USA. e-mail: burggren@unt.edu
Swimming stamina in adult fish is heritable, it is unknown if inherited traits that support enhanced swimming stamina in offspring appear only in juveniles and/or adults, or if these traits actually appear earlier in the morphologically quite different larvae. To answer this question, mature adult zebrafish (Danio rerio) were subjected to a swimming performance test that allowed separation into low swimming stamina or high swimming stamina groups. Adults were then bred within their own performance groups. Larval offspring from each of the two groups, designated high ( $\left.\mathrm{L}_{\mathrm{HSD}}\right)$ and low stamina-derived larvae $\left(\mathrm{L}_{\mathrm{LSD}}\right)$, were then reared at $27^{\circ} \mathrm{C}$ in aerated water $\left(21 \% \mathrm{O}_{2}\right)$. Routine $\left(\mathrm{f}_{\mathrm{H}}, \mathrm{r}\right)$ and active $\left(\mathrm{f}_{\mathrm{H}}, \mathrm{a}\right)$ heart rate, and routine $\left(\dot{M}_{2}, r\right)$ and active $\left(\dot{M}_{2}, a\right)$ mass-specific oxygen consumption were recorded from 5 days post fertilization (dpf) through $21 \mathrm{dpf}$, and gross cost of transport and factorial aerobic metabolic scope were derived from $\dot{M}_{2}$ measurements. Heart rate generally ranged between 150 and $225 \mathrm{bpm}$ in both $L_{H S D}$ and $L_{L S D}$ populations. However, significant $(P<0.05)$ differences existed between the $L_{L S D}$ and $L_{H S D}$ populations at 5 and $14 \mathrm{dpf}$ in $\mathrm{f}_{H}, \mathrm{r}$ and at days 10 and $15 \mathrm{dpf}$ in $\mathrm{f}_{\mathrm{H}}, \mathrm{a} . \dot{M} \mathrm{o}_{2}, \mathrm{r}$ was $0.04-0.32 \mu \mathrm{mol} \mathrm{mg}^{-1} \mathrm{~h}^{-1}$, while $\dot{M} \mathrm{O}_{2}$, a was $0.2-1.2 \mu \mathrm{mol} \mathrm{mg} \mathrm{m}^{-1} \mathrm{~h}^{-1}$. Significant $(P<0.05)$ differences between the $L_{L S D}$ and $L_{H S D}$ populations in $\dot{M} \mathrm{O}_{2}$, r occurred at 7, 10 , and $21 \mathrm{dpf}$ and in $\dot{M} \mathrm{o}_{2}$, a at $7 \mathrm{dpf}$. Gross cost of transport was $\sim 6-10 \mu \mathrm{mol} \mathrm{O}_{2} \cdot \mu^{-1} \mathrm{~m}^{-1}$ at $5 \mathrm{dpf}$, peaking at $14-19 \mu \mathrm{mol} \mathrm{O}_{2} \mu \mathrm{g}^{-1} \mathrm{~m}^{-1}$ at $7-10 \mathrm{dpf}$,

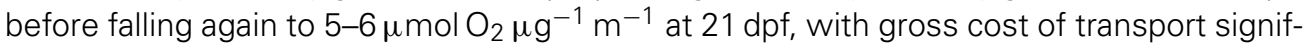
icantly higher in the $L_{L S D}$ population at $7 \mathrm{dpf}$. Collectively, these data indicate that inherited physiological differences known to contribute to enhanced stamina in adult parents also appear in their larval offspring well before attainment of juvenile or adult features.

Keywords: zebrafish, cardio-respiratory physiology, inherited traits, swimming stamina

\section{INTRODUCTION}

Individual fishes capable of elevated swimming speeds and/or showing enhanced stamina tend to exhibit longer lengths, have a higher percentage of skeletal muscle as a proportion of total body mass, and show higher metabolic scope for activity when compared with other individuals from a general population (for reviews, see Farrell, 2002; Claireaux et al., 2005; Claireaux and Lefrançois, 2007; Farrell, 2007; Clark et al., 2011). While the morphological and physiological underpinnings of enhanced locomotor performance in adult fish are well understood, relatively few studies have considered these topics in larval fishes. However, the literature on the energetics and physiology of larval fish locomotion has been expanding, driven by relevance to ecology, environment, and aquaculture as well as fundamental physiological questions (for an entry in to the literature, see Leis, 2006; Hurst et al., 2007; Nilsson et al., 2007; MacPhail et al., 2009; Lindsey et al., 2010; Colwill and Creton, 2011). Numerous studies, often on larval zebrafish, have begun to reveal the interrelationships between metabolic activity, swimming patterns during development, and developmental changes in heart and axial muscle development (see for example Müller et al., 2000; Bagatto et al., 2001; Pelster et al., 2003; Müller and van Leeuwen, 2004; Thorsen et al., 2004; van der Meulen et al., 2006; McLean and Fetcho, 2009).
Despite this expansion of studies on the locomotory energetics and physiology of larval fish, most studies on the heritability of fish locomotor energetics and mechanics have remained focused on adult stages - either as adult parents or adult offspring. Elevated swimming performance in fishes is certainly a heritable trait subject to natural selection (e.g., Evans et al., 2004; Langerhans et al., 2004). For example, Langerhans et al. (2004) demonstrated that populations of mosquito fish (Gambusia affinis) subjected to high levels of predation had evolved a larger caudal fin, longer body, a more ventral-posterior eye location, and faster burst speeds, when compared to populations that experience lower predation levels. These morphological differences persisted into subsequent generations, suggesting a heritable component to these modifications for improved locomotor performance and prey avoidance. There is some evidence that not just the trait of elevated swim performance, but also degraded swim performance, can cross generations. For example, the parr stage of sockeye salmon (Oncorhynchus nerka) show degraded swimming performance when derived from adult females that were moribund at the end of migration for spawning (Tierney et al., 2009). Offspring growth was not affected, but physiological indicators such as plasma lactate concentration in post-exercise state, typically used as an indicator of white muscle use, was greater for parr derived from moribund adult females. 
Finally, swimming-related behaviors appear heritable, as well, with schooling behaviors specific to marine and fresh-water environments are inherited by the adult offspring of the three-spine stickleback (Gasterosteus aculeatus; Wark et al., 2011).

Few studies, however, have attempted to link swimming performance in reproducing adult fishes directly to the physiological characteristics of their own larval offspring, as opposed to their offspring once reaching adulthood. Enhanced performance of the physiological systems vital in the support of swimming - e.g., cardiovascular and respiratory systems - are very likely to be inherited along with specific locomotor muscle genotypes, since these support systems are vital to enhanced swimming performance in adults and larvae alike. Yet, the heritable nature of physiological performance characteristics (e.g., routine and active heart rate, routine and active oxygen consumption, metabolic scope for activity) has yet to be explored in any depth.

In considering the inheritance of traits associated with physiological systems in support of locomotion in fishes, a fundamental question arises: "Do adults with enhanced swimming capabilities pass on associated traits that only subsequently appear in their offspring as adults, or are these traits expressed in their offspring even in early developmental stages"? To answer this question, this study focuses on cardio-respiratory and swimming performance in zebrafish $(D$. rerio) to generate a better understanding of transgenerational transfer of swimming-related physiological performance in Teleost fishes. We hypothesize that the onset of physiological processes potentially supporting enhanced swimming stamina appear early in larval development, and well before the attainment of adult morphology. To test this hypothesis, we have categorized adult reproducing zebrafish as having high, average, or low swimming stamina by employing time-toexhaustion tests, and then investigated at what time in development their respective offspring begin to show differences in routine and maximum heart rate, and routine and maximum oxygen consumption.

\section{MATERIALS AND METHODS ANIMALS}

Adult zebrafish were acquired from local suppliers (University of North Texas zebrafish colony and the Dallas North Aquarium). All animal and experimental protocols were reviewed and approved by the Institutional Animal Care and Use Committee of University of North Texas.

Adult fish were maintained in aquaria (volume 18.91) with constant temperature $\left(27^{\circ} \mathrm{C}\right)$ and aeration $\left(21 \% \mathrm{O}_{2}\right)$. Adults were fed brine shrimp ad libitum twice daily for 14 days leading up to evaluation of their swimming stamina. After swimming evaluation, feeding was increased to three times daily to create top breeding condition. Mass, length, and width (measured behind the pectoral fin) of each adult fish was recorded prior to further experimentation. Condition factor $(K)$, a measure of a fish's girth (Reid et al., 2005), was also calculated for these fish using the formula:

$K=100 \mathrm{BW} \mathrm{TL}^{-3}$

where $\mathrm{BW}=$ body weight $(\mathrm{g})$ and $\mathrm{TL}=$ total length $(\mathrm{cm})$.

\section{SWIMMING PROTOCOL AND STAMINA EVALUATION}

Adult stamina classification was determined in a gravity-fed "water treadmill” system providing fine control of water velocity and temperature $\left(27^{\circ} \mathrm{C}\right)$, after Bagatto et al. (2001). The treadmill consisted of a series of polyvinylchloride swimming tubes (inside diameter $=4 \mathrm{~cm}$; length $45 \mathrm{~cm}$; volume $180 \mathrm{ml}$ ) gravity-fed with aerated water from an upper water reservoir. Water from the tubes drained into a bottom reservoir and was then pumped back up to the upper reservoir for aeration. A filtration system inside the lower reservoir maintained appropriate water chemistry and filtered out large particulate matter. Total volume of the system was $\sim 68$ l. Each swimming tube was open to the atmosphere along the length of its top to allow access to the swimming larva, as well as to admit ambient lighting. A $20-\mathrm{cm}$ long swimming area in each tube was defined at its upper and lower ends by a cluster of drinking straw pieces packed together in a $3-\mathrm{cm}$ thick parallel array. Water flowed through this straw cluster in a highly laminar fashion, maintaining laminar flow through the swimming area of the tube.

To determine stamina, adults were very carefully netted from the general holding tank and quickly transferred to the swim tubes, taking care to treat each fish identically and in a manner minimizing the level of induced stress of handling. Randomly selected pair of adults was placed in each of three swim tubes. After a 30min rest period in a zero velocity current, water velocity was then increased to the test current of $\sim 7.5 \mathrm{bl} \mathrm{s}^{-1}$ which is $\sim 50 \%$ of the $U_{\text {crit }}$ established for adult zebrafish of near identical size to those of the present study (Plaut and Gordon, 1994). The first two of the six zebrafish to become physically exhausted, as determined by their being swept back and pinned against the rear barrier of straws, were classified as "low stamina" swimmers. Typically the first two fish reached exhaustion in $<10 \mathrm{~min}$, at which point they were removed and placed in the "low stamina fish" holding tank containing aerated water The next two fish to become exhausted according to this test protocol were classified as "average" swimmers ( 10-20 min), and similarly were removed and placed in a separate holding tank. Finally, the last two fish to become exhausted, generally after $>20$ min of swimming, were classified as "high stamina" swimmers. This process was repeated until three separate groups of 28 adults each (equal number of males and females) were created based on swimming stamina (Table 1).

\section{BREEDING PROTOCOL}

One week after determination of swimming stamina, four adult zebrafish from each of the low stamina and high stamina groups were bred strictly within their respective stamina groups. Individual breeding tanks with controlled temperature $\left(27^{\circ} \mathrm{C}\right)$ and light conditions ( $14 \mathrm{~h}$ light: $10 \mathrm{~h}$ dark) were established with a ratio of two females to two males. Adults were placed in the breeding tanks in the late afternoon, where they remained overnight. The next morning fertilized eggs were collected from the breeding tanks using a disposable plastic pipette, and were transferred into containers containing all of the eggs for a specific stamina group.

\section{LARVAL CLASSIFICATION}

Larvae derived from the breeding of high stamina adults were designated as "high stamina-derived larvae" $\left(\mathrm{L}_{\mathrm{HSD}}\right)$ Larvae derived 
Table 1 | Morphometrics and condition factor, $K$, in adult male and female zebrafish classified according to swimming stamina.

\begin{tabular}{lllllll}
\hline Group & & $\boldsymbol{n}$ & Mass $(\mathbf{g})$ & Length $(\mathbf{c m})$ & Width (cm) & Condition factor, $\boldsymbol{K}\left(\mathbf{1 0 0} \mathbf{g ~ c m} \mathbf{~}^{-3}\right.$ ) \\
\hline High stamina adults & Male & 14 & $0.22 \pm 0.01^{\mathrm{a}}$ & $3.23 \pm 0.03^{\mathrm{a}, \mathrm{b}}$ & $0.31 \pm 0.01^{\mathrm{a}}$ & $0.63 \pm 0.03^{\mathrm{a}}$ \\
& Female & 14 & $0.31 \pm 0.02$ & $3.36 \pm 0.02$ & $0.35 \pm 0.03$ & $0.87 \pm 0.07$ \\
Average stamina adults & Male & 14 & $0.20 \pm 0.01^{\mathrm{a}}$ & $3.22 \pm 0.05^{\mathrm{a}}$ & $0.26 \pm 0.01^{\mathrm{a}}$ & $0.60 \pm 0.02^{\mathrm{a}}$ \\
& Female & 14 & $0.26 \pm 0.01$ & $3.29 \pm 0.06$ & $0.31 \pm 0.01$ & $0.73 \pm 0.03$ \\
Low stamina adults & Male & 14 & $0.18 \pm 0.02^{\mathrm{a}}$ & $3.05 \pm 0.06^{\mathrm{a}}$ & $0.25 \pm 0.01^{\mathrm{a}}$ & $0.51 \pm 0.06^{\mathrm{a}}$ \\
& Female & 14 & $0.34 \pm 0.03$ & $3.46 \pm 0.05$ & $0.34 \pm 0.02$ & $0.95 \pm 0.07$ \\
\hline
\end{tabular}

Values are means \pm 1 SE. a Significantly different than females of same stamina group; ${ }^{b}$ significantly different than low stamina males.

from the breeding of low stamina adults were designated as low stamina-derived larvae $\left(\mathrm{L}_{\mathrm{LSD}}\right)$.

\section{LARVAL GROWTH RATES}

Larvae were maintained at a constant temperature $\left(27^{\circ} \mathrm{C}\right)$, oxygen level $\left(21 \% \mathrm{O}_{2}\right)$, and light cycle ( $14 \mathrm{~h}$ light: $10 \mathrm{~h}$ dark) throughout their development. All larvae were fed brine shrimp ad libitum three times daily. The initial weight and length of immature fish were recorded at 2 and 21 days post fertilization (dpf) to assess differences in the rate of growth between performance groups. Mass-specific growth rates were calculated using Ricker's (1979) formula:

$\mathrm{GR}=100\left(W_{2}-W_{1}\right) / 0.5\left(W_{1}+W_{2}\right) / T$

where $W_{1}$ and $W_{2}=$ initial and final weights $(\mathrm{mg})$ recorded over the time $(T)$ in days, and $\mathrm{GR}=$ growth rate as a $\%$ change.

\section{HEART RATE MEASUREMENTS \\ Routine heart rate $\left(f_{H}, r\right)$}

The small size and erratic movements of unrestrained zebrafish larvae unfortunately precluded visual observation of heart rate over more than several seconds. Consequently, to quantify heart rate, high stamina-derived, and low stamina-derived larvae were partially confined by drawing them up into an eye dropper and then gently placing them individually into a water-filled transparent glass capillary tube with an inside diameter of $1.4 \mathrm{~mm}$. This measurement method has previously been shown to allow for 30-50 s observation periods without inducing high stress levels (Barrionuevo and Burggren, 1999). The entire period of time in the capillary tube was less than $60 \mathrm{~s}$, minimizing the chances of significant changes in the temperature or $\mathrm{PO}_{2}$ of water within the capillary tube. Each larva in its tube was then immediately placed on a temperature controlled $\left(27^{\circ} \mathrm{C}\right)$ stage of a Nikon inverted microscope for imaging of the beating heart. Heart images were recorded with a Javelin Electronics camera (model JE3010), stored on a computer, and then analyzed with ImagePro Plus software. Routine heart rate was determined by counting the number of heart beats in a 15-s period from the video images, and then calculating heart rate in beats per minute. While this process may have induced some modest stress in larvae, importantly the "routine" heart rate was typically 20-40 bpm below "active" heart rate in our measurements, suggesting that routine heart rates were far more reflective of resting than maximally stimulated rates of stressed larvae.
Routine heart rate was measured in both $\mathrm{L}_{\mathrm{HSD}}$ and $\mathrm{L}_{\mathrm{LSD}}$, beginning at $3 \mathrm{dpf}$ and continued on 5, 7, 10, 14, and $21 \mathrm{dpf}$.

\section{Active heart rate $\left(f_{H}, a\right)$}

Active heart rate was determined by swimming each larva in a gravity-fed swim system that was essentially a miniaturized version of that described above for swimming adults. This system consisted of a 3.6-1 reservoir and a swim chamber (inside diameter $1 \mathrm{~cm}$; length $3 \mathrm{~cm}$; volume $3 \mathrm{ml})$. Water temperature $\left(27^{\circ} \mathrm{C}\right)$ and volume were maintained throughout swim training periods, and flow rate was controlled using a variable position stopcock. Each larva was first placed in still water $\left(0 \mathrm{bl} \mathrm{s}^{-1}\right)$ for a 5-min acclimation period. Water current speed was rapidly $(<2 \mathrm{~s})$ increased to $\sim 4.5 \mathrm{bl} \mathrm{s}^{-1}$. Each fish was then exposed to this current for $2 \mathrm{~min}$. At the end of the 2-min period, larvae were removed with a disposable plastic pipette, transferred to a capillary tube and heart rate immediately assessed as described above. Total time elapsed from end of the swimming bout to the end of the heart rate determination was $<25 \mathrm{~s}$. These larvae were then placed in a separate container to eliminate inadvertent repeated measurements on the same larva.

Active heart rate was determined by counting the number of heart beats in a 15-s period and then calculating heart rate in beats per minute. Active heart rate was measured in larvae beginning at $5 \mathrm{dpf}$ and was continued on $7,10,14$, and $21 \mathrm{dpf}$.

\section{OXYGEN CONSUMPTION MEASUREMENTS Routine oxygen consumption $\left(\dot{M}_{2}, r\right)$}

Routine oxygen consumption $\left(\dot{M}_{2}, \mathrm{r}\right)$ was determined for larvae and juveniles using conventional closed system respirometry for aquatic vertebrate larvae (e.g., Hastings and Burggren, 1995; Territo and Burggren, 1998; Rogge and Warkentin, 2008). Each respirometer consisted of a 2.0-ml glass syringe filled with $1 \mathrm{ml}$ with water, with an attached needle sealed by a rubber stopper. Respirometers containing larvae were kept in a temperature controlled $\left(27^{\circ} \mathrm{C}\right)$ water bath (Forma Scientific, model 2006) for $1 \mathrm{~h}$ before measurements to allow larvae to acclimate to the respirometers. The water was very gently renewed with air-equilibrated water immediately before the beginning of the oxygen consumption measurement period. Care was taken to minimize any disturbance to the larva within, as induced stress solely from handling would reduced metabolic scope by increasing the apparent $\dot{M} \mathrm{o}_{2}, \mathrm{r}$. We presume minimal stress in the larvae during these tests, as every larva was given a lengthy acclimation period and showed no behavioral changes during replacement of water immediately 
before measurements were started. The $\mathrm{PO}_{2}$ of water from the respirometer was measured by injecting water from the syringe directly into a small cuvette containing an oxygen microelectrode (Microelectrodes, Inc., Bedford, NH, USA), providing input into a Chart data acquisition program (PowerLab). The $\mathrm{PO}_{2}$ of water in the respirometer typically declined by $5-10 \mathrm{mmHg}$ during the measurement period, depending upon larval age. Oxygen consumption $\left(\dot{M}_{2}, \mu \mathrm{mol} \mathrm{O}_{2} \mathrm{mg}^{-1} \mathrm{~h}^{-1}\right)$ was calculated using the formula:

$\dot{M}_{2}=\frac{\Delta \mathrm{PO}_{2} \alpha V}{\Delta t m}$

where $\Delta \mathrm{PO}_{2}=$ decrease in partial pressure of $\mathrm{O}_{2}$ in the respirometer in $\mathrm{mmHg}, \alpha=\mathrm{O}_{2}$ capacitance of water at $27^{\circ} \mathrm{C}$ in $\mu \mathrm{moll}^{-1} \mathrm{mmHg}^{-1}, V=$ initial volume in the respirometer in $\mathrm{ml}$, $\Delta t=$ elapsed time in $\mathrm{h}$, and $m=$ mass in $\mathrm{mg}$.

\section{Active oxygen consumption $\left(\dot{M}_{2}, a\right)$}

Active oxygen consumption $\left(\dot{M}_{2}\right.$, a), the oxygen consumption evident during swimming at a constant velocity of $\sim 4.5 \mathrm{bl} \mathrm{s}^{-1}$, was determined in larvae by using modified closed respirometry with a miniaturized Brett swimming respirometer (Beamish, 1979). Each swim respirometer consisted of four pieces of glass tubing ( $5 \mathrm{~mm}$ inside diameter) joined together to form a raceway in the shape of a rectangle $\sim 10 \mathrm{~cm}$ on edge. This assembly also had two sample ports, a glass two-way stopcock, and a small magnetic water pump, all in series (for details, see Bagatto et al., 2001). The respirometer was initially filled with air-saturated water and then 10 larvae $(5 \mathrm{dpf})$ or 5 larvae (older than $5 \mathrm{dpf}$ ) were carefully placed into the respirometer. All larvae were made to swim at a water current velocity of $5 \mathrm{bl} \mathrm{s}^{-1}$ for a minimum of $60 \mathrm{~min}$ before water was sampled for $\mathrm{PO}_{2} . \dot{M} \mathrm{o}_{2}$, a was measured beginning at $5 \mathrm{dpf}$ and continued on 7,10,14, and finally ending on $21 \mathrm{dpf}$, the chronological age of transition from larvae to juveniles. All larvae in each age class were of almost identical length, evident by the small error bars in the body length data (see Figure 1).

\section{AEROBIC SCOPE AND GROSS COST OF TRANSPORT}

Factorial aerobic scope was calculated for larval fish by dividing $\dot{M}_{\mathrm{o}_{2}}$, a by $\dot{M} \mathrm{o}_{2}$, r. As a measure of swimming efficiency, gross cost of transport, expressed as $\mu \mathrm{mol} \mathrm{O}_{2} \mu \mathrm{g}$ body mass ${ }^{-1} \mathrm{~m}^{-1}$ traveled, was calculated using $\dot{M} \mathrm{o}_{2}$, a, larval body mass, and distance traveled in the respirometer by each larva.

\section{LARVAL SWIMMING STAMINA}

Unlike the swimming behavior of adults that allows for swimming stamina to be determined over a 10 - to 30 -min period, larval swimming behavior is characterized by intermittent bursts of swimming (e.g., Bagatto and Burggren, 2001). This precluded determination of a comparable measure of swimming stamina in the current study.

\section{STATISTICAL ANALYSES}

Comparison of low stamina and high stamina adults was performed using a one-way ANOVA, followed by a StudentNewman-Keuls test to determine pair-wise differences. Parametric two-way ANOVAs were used to assess the statistical differences

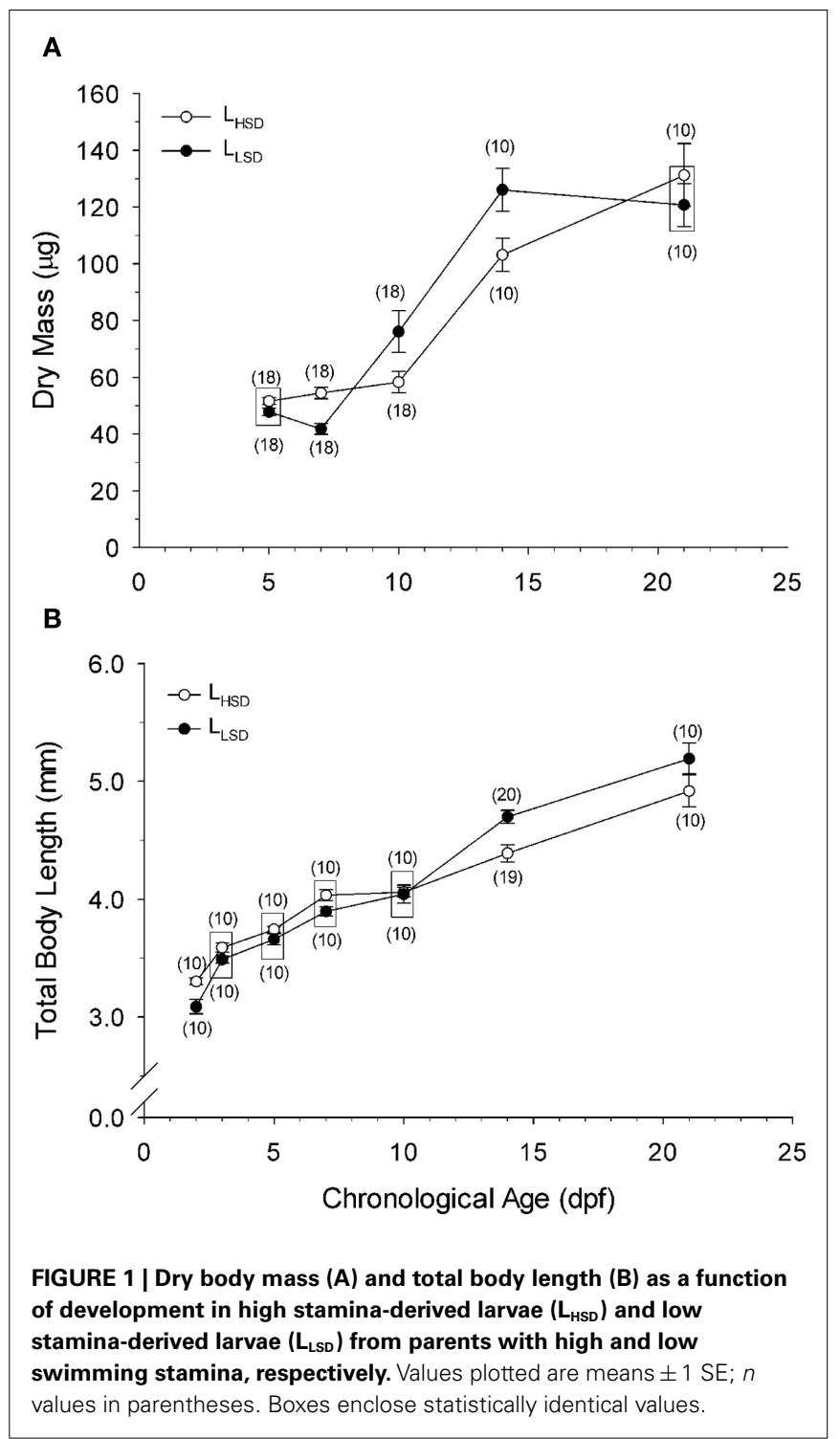

between offspring lengths, masses, heart rates, metabolic rates, and cost of transport of larvae from high stamina and low stamina swimmers (unless otherwise noted). If the two-way ANOVA was significant, then post hoc tests were used to make pair-wise comparisons. Once a measurement was made on an adult or larvae, that individual was removed from the pool of animals used for subsequent measurements, eliminating any possibility of pseudoreplication. All variables are represented as mean $\pm 1 \mathrm{SE}$ and statistical significance level is set at $0.05(P<0.05)$. All statistical analyses were performed using SigmaStat ${ }^{\circledR}$ and SigmaPlot ${ }^{\circledR}$ software.

\section{RESULTS}

\section{ADULT MORPHOMETRICS}

Body mass, width, length, and condition factor $(K)$ for adult males were all significantly lower $(P<0.05)$ than females, both within and between groups (Table 1). Adult male fish classified as low stamina swimmers had significantly shorter bodies $(P<0.01)$ than 
high stamina male swimmers. However, unlike in males, there were no significant differences $(P>0.05)$ in body length in low and high stamina females.

Body masses in high stamina adult males and adult females were not significantly different $(P>0.05)$ from low stamina males and females, respectively. Only males showed a significant intergroup difference $(P<0.05)$ in body width.

\section{LARVAL GROWTH RATE}

High stamina larvae $\left(\mathrm{L}_{\mathrm{HSD}}\right)$ and low stamina larvae $\left(\mathrm{L}_{\mathrm{LSD}}\right)$ had identical initial body dry masses of $50 \pm 1 \mathrm{mg}$ early in development and at $5 \mathrm{dpf}$, but thereafter diverged, with the largest mass differences occurring at 10 and $15 \mathrm{dpf}(P<0.05$; Figure 1). By $21 \mathrm{dpf}$ the body mass was $130 \pm 10 \mathrm{mg}$ for $\mathrm{L}_{\mathrm{HSD}}$, not significantly different from $120 \pm 10 \mathrm{mg}$ for $\mathrm{L}_{\mathrm{LSD}}$, and therefore, larval growth was not significantly affected by stamina group $(P>0.05)$. However, as expected, body mass increased with developmental stage affected $(P<0.001)$, but significant differences between $\mathrm{L}_{\mathrm{HSD}}$ and $\mathrm{L}_{\mathrm{LSD}}$ existing at 7,10 , and $14 \mathrm{dpf}(P<0.05)$.

Body length of course increased significantly during development in both populations $(P<0.01)$ early in development at $2 \mathrm{dpf}$ was $3.30 \pm 0.03 \mathrm{~mm}$ in $\mathrm{L}_{\mathrm{HSD}}$ but slightly but significantly lower at $3.10 \pm 0.06 \mathrm{~mm}$ in $\mathrm{L}_{\mathrm{LSD}}$. Body lengths at 15 and $21 \mathrm{dpf}$ were significantly greater in $\mathrm{L}_{\mathrm{LSD}}$ compared to $\mathrm{L}_{\mathrm{HSD}}$ (Figure 1B).

Calculated growth rates at $21 \mathrm{dpf}$, using Ricker's (1979) formula based on body mass, were nearly identical in $\mathrm{L}_{\mathrm{HSD}}\left(5.44 \%\right.$ day $^{-1}$ ) and $\mathrm{L}_{\mathrm{LSD}}\left(5.41 \% \mathrm{day}^{-1}\right)$.

\section{ROUTINE AND ACTIVE HEART RATE}

Heart rate differed significantly between larvae from low and high stamina parents (two-way ANOVA on ranks, $P<0.05$; Figure 2). $\mathrm{L}_{\mathrm{LSD}}$ had significantly higher routine heart rates at 7 , and 14 and $21 \mathrm{dpf}(P<0.001) . \mathrm{f}_{\mathrm{H}}$, a recorded from $\mathrm{L}_{\mathrm{HSD}}$ and $\mathrm{L}_{\mathrm{LSD}}$ (Figure 2) were also significantly different (two-way ANOVA on ranks, $P<0.05)$, with the $\mathrm{L}_{\mathrm{LSD}}$ showing significantly higher $\mathrm{f}_{\mathrm{H}}$, a at 10 and $14 \mathrm{dpf}(P<0.05$ and $P<0.001)$. There were also significant differences between $\mathrm{f}_{\mathrm{H}}, \mathrm{r}$ and $\mathrm{f}_{\mathrm{H}}, \mathrm{a}$ within $\mathrm{L}_{\mathrm{HSD}}(P<0.001)$ and $\mathrm{L}_{\mathrm{LSD}}(P<0.001)$, with a higher $\mathrm{f}_{\mathrm{H}}$, a for all developmental stages.

\section{OXYGEN CONSUMPTION}

Routine oxygen consumption showed significant differences $(P<0.05)$ between $\mathrm{L}_{\mathrm{HSD}}$ and $\mathrm{L}_{\mathrm{LSD}}$ (Figure 3). $\dot{M} \mathrm{o}_{2}$, r was significantly lower in $\mathrm{L}_{\mathrm{LSD}}$ than $\mathrm{L}_{\mathrm{HSD}}$ at 7 and $21 \mathrm{dpf}(P<0.05)$, and was significantly higher at $10 \mathrm{dpf}(P<0.05) . \dot{M} \mathrm{o}_{2}$, a in $\mathrm{L}_{\mathrm{LSD}}$ was not significantly different $(P>0.10)$ from $\mathrm{L}_{\mathrm{HSD}}$, except at $7 \mathrm{dpf}$ when $\dot{M} \mathrm{o}_{2}$, a of $\mathrm{L}_{\mathrm{LSD}}$ was significantly higher than $\mathrm{L}_{\mathrm{HSD}}(P<0.05)$. $\dot{M} \mathrm{o}_{2}$, a was also significantly higher than $\dot{M} \mathrm{o}_{2}, \mathrm{r}$ within groups at all developmental stages $(P<0.001)$.

\section{AEROBIC SCOPE}

Aerobic scopes differed in both degree and kind between $\mathrm{L}_{\mathrm{HSD}}$ and $\mathrm{L}_{\mathrm{LSD}}$. Aerobic scope in $\mathrm{L}_{\mathrm{HSD}}$ was initially 3.3 at $5 \mathrm{dpf}$, increasing to 5.1 at $10 \mathrm{dpf}$ before decreasing once again with further development (Figure 4). However, in $\mathrm{L}_{\mathrm{LSD}}$, aerobic scope was initially 6.0 at $5 \mathrm{dpf}$, decreasing to 1.2 at $14 \mathrm{dpf}$ before increasing once again. The aerobic scopes of $\mathrm{L}_{\mathrm{LSD}}$ were 82,109 , and $139 \%$ higher than $\mathrm{L}_{\mathrm{HSD}}$ at 5,7 , and $21 \mathrm{dpf}$, respectively. Aerobic scopes of $\mathrm{L}_{\mathrm{HSD}}$ were 102 and $18 \%$ higher than $\mathrm{L}_{\mathrm{LSD}}$ at 10 and $14 \mathrm{dpf}$, respectively.
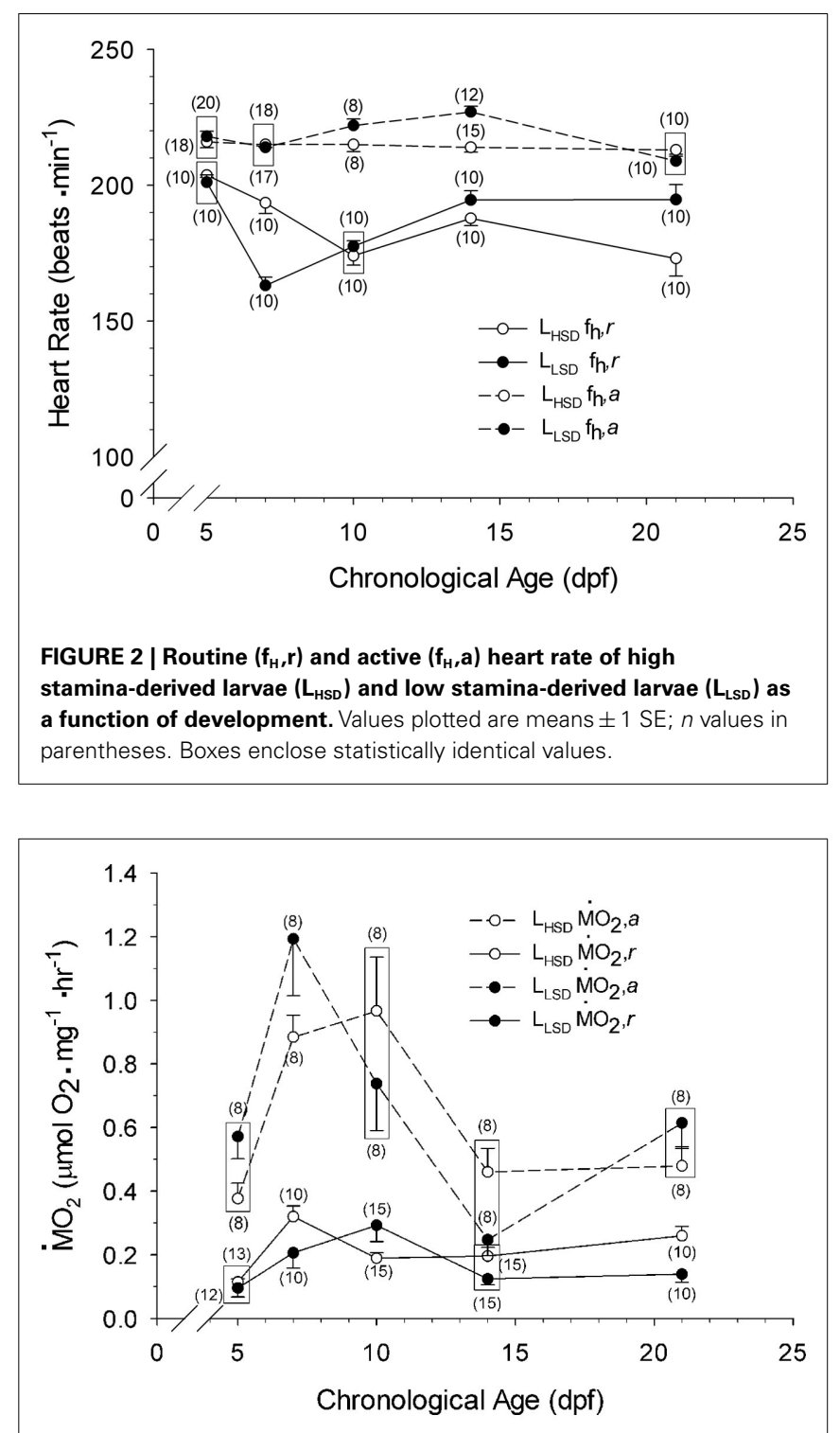

FIGURE 3 | $\dot{M} \mathrm{o}_{2}, \mathrm{r}$ and $\dot{M} \mathrm{o}_{2}$, a of high stamina-derived larvae ( $\mathrm{L}_{\mathrm{HSD}}$ ) and low stamina-derived larvae ( $L_{L S D}$ ) as a function of development. Values plotted are means $\pm 1 \mathrm{SE} ; n$ values in parentheses. Boxes enclose statistically identical values.

\section{GROSS METABOLIC COST OF TRANSPORT}

Gross cost of transport ranged from 3 to $19 \mu \mathrm{mol} \mathrm{O}_{2} \mu \mathrm{g}$ body mass ${ }^{-1} \mathrm{~m}^{-1}$ over the course of development, peaking at 7 and $10 \mathrm{dpf}$ in $\mathrm{L}_{\mathrm{LSD}}$ and $\mathrm{L}_{\mathrm{HSD}}$, respectively (Figure 5). Gross cost of transport was only significantly higher in $\mathrm{L}_{\mathrm{LSD}}$ compared to $\mathrm{L}_{\mathrm{HSD}}$ at $7 \mathrm{dpf}(P<0.05)$.

\section{DISCUSSION \\ ADULT MORPHOMETRICS AND SWIMMING STAMINA}

Body shape plays a major role in fish hydrodynamics, swimming speed and stamina (e.g., Martínez et al., 2004;; Müller et al., 2008; Porter et al., 2011). In the present study, however, intraspecific variations in body shape appear to have little effect on swimming 


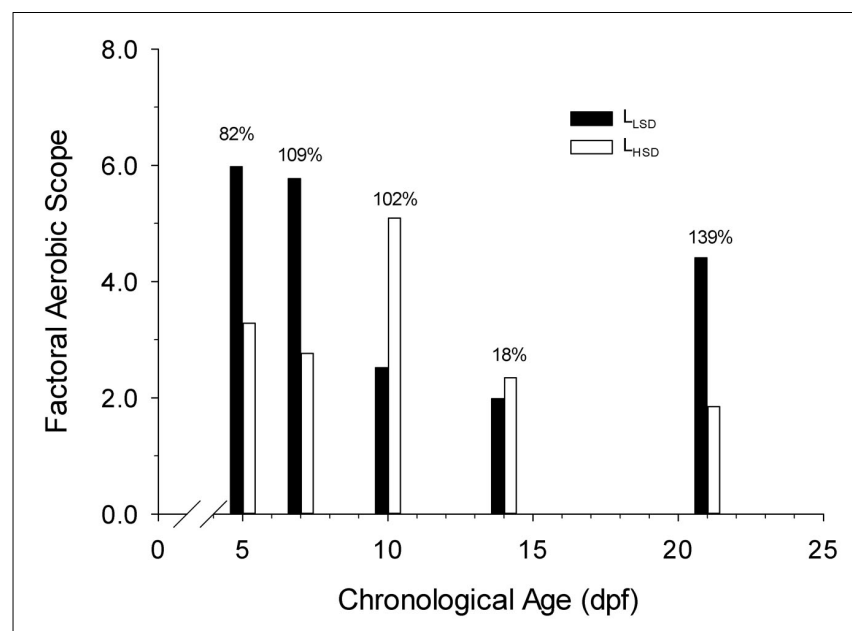

FIGURE 4 | Factorial aerobic scope of high stamina-derived larvae ( $\mathrm{L}_{\mathrm{HSD}}$ ) and low stamina-derived larvae $\left(L_{L S D}\right)$ as a function of development.

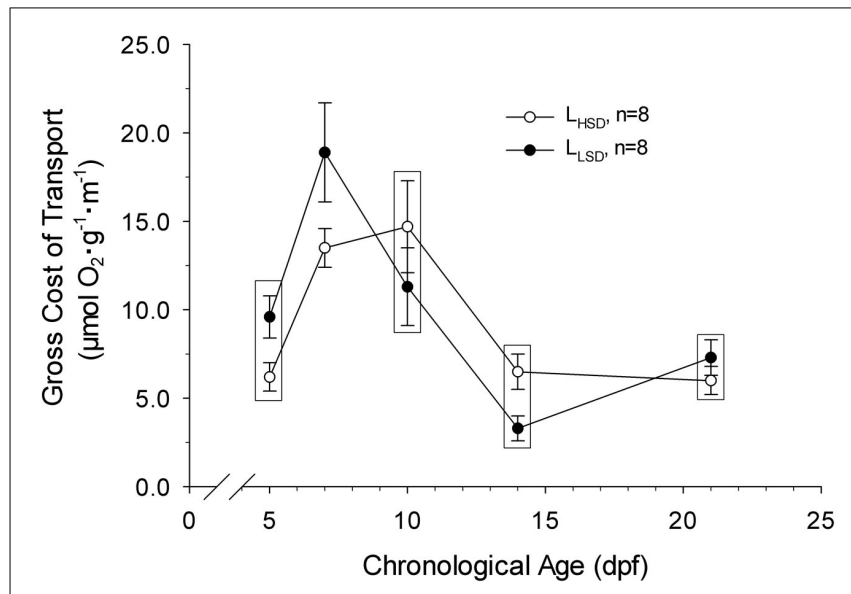

FIGURE 5 | Gross Cost of transport in high stamina-derived larvae ( $\mathrm{L}_{\mathrm{HSD}}$ ) and low stamina-derived larvae $\left(\mathrm{L}_{\mathrm{LSD}}\right)$ as a function of development. Values plotted are means \pm 1 SE. Boxes enclose statistically identical values.

stamina of adult zebrafish, at least when assessed by simple body dimension variables. The only significant dimensional difference observed in the present study was a greater body length in high stamina males when compared with low stamina males and when compared with both female groups (Table 1). Condition factor, $K$, was lower in males than in females in all three groups, despite identical regimes for feeding and care. Indeed, the role of body mass on the physiology of fishes, including swimming activity, is still poorly understood (see Clark and Farrell, 2011). Multiple mechanisms could account for the differences seen in swimming stamina in adult fish, and their identification will comprise an interesting future study.

\section{LARVAL GROWTH RATES}

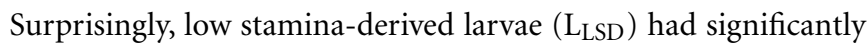
higher dry masses at 7, 10, and $14 \mathrm{dpf}$, and greater length by 14 and
$21 \mathrm{dpf}$. The physiological implications of these larval dry mass differences, are as yet unknown, as are the likely causes of these differences. Both abiotic and biotic factors influence the growth of larval fishes, and these rates often vary greatly both intra- and inter-specifically (for an introduction to the extensive literature, see Pelster, 2002; Arnott et al., 2006; Hunt von Herbing, 2006; Johnston, 2006; Rombough, 2006; Finn, 2007; Johnston et al., 2011). Abiotic factors and food availability are unlikely to be causal agents for the differences observed in our study, given our careful control of experimental conditions. However, competition for food - as opposed to food availability - was not controlled for in our study, and could have led to differential growth rates, as seen for juvenile gilthead sea bream, Sparus aurata (Goldann et al., 2003), and cod (Hart and Salvanes, 2000).

\section{HEART RATE}

Resting heart rates in larval zebrafish from 2 to $21 \mathrm{dpf}$ reported in the present study compares favorably with that of previous studies under comparable temperatures and holding conditions (see Barrionuevo and Burggren, 1999; Pelster et al., 2003; Schwerte et al., 2005; Bagatto and Burggren, 2001; Burggren and Bagatto, 2008; Barrionuevo et al., 2010). Generally, there was a 20- to 50-beat $\min ^{-1}$ increase in heart rate associated with swimming activity beginning as early as day 5 , suggesting that neural and/or hormonal mechanisms necessary for heart rate acceleration are functional in early development, in alignment with both gene knock-out and pharmaceutical studies of zebrafish larvae (e.g., Schwerte et al., 2006; Steele et al., 2011). The present study also shows that statistically significant differences between $\mathrm{L}_{\mathrm{HSD}}$ and $\mathrm{L}_{\mathrm{LSD}}$ in both routine and active heart rates emerge by $10 \mathrm{dpf}$ (Figure 2). For example, at $14 \mathrm{dpf}$, larvae derived from low stamina parents exhibited significantly higher heart rates than high stamina-derived larvae at both rest and during activity. By $21 \mathrm{dpf}$ there was no difference in active heart rate between populations, but heart rate at rest was approximately $10-15 \%$ lower in $\mathrm{L}_{\mathrm{HSD}}$ compared with $\mathrm{L}_{\mathrm{LSD}}$. What these differences in heart rate translate into in terms of cardiac output, tissue perfusion, and $\mathrm{O}_{2}$ delivery is at present unknown. At least in adult fishes, heart rate can be a relatively accurate indicator of overall cardiac performance and cardiac output, because in many species increases in cardiac output are achieved primarily by increases heart rate rather than stroke volume (e.g., Burggren et al., 1996; Sandblom et al., 2005; Clark and Seymour, 2006) - though this is not universal trait (c.f. Webber et al., 1998). If cardiac output in larval zebrafish is similarly closely correlated with heart rate, the lower routine, and active heart rate values for $\mathrm{L}_{\mathrm{HSD}}$ zebrafish in the present study could reflect lower cardiac output for any given swimming speed in this high stamina- derived group, which is a trait of "athletes" throughout the vertebrates. Swimming capabilities in zebrafish larvae depend upon not only cardiac output, but also upon tissue level characteristics such as mitochondrial and capillary density (Pelster et al., 2003). Whether the physiological implications of our measured differences in routine and active heart rate in larval zebrafish are adaptive (i.e., improve larval or juvenile swim performance) or are merely reflections of the consequence of genetic changes that impart improved performance in the parents, these differences in larvae do indeed correlate with parental stamina. Thus, emergence of this inherited physiological 
phenotype does not require full development to juvenile stages or full maturation to adulthood, in support of our proposed hypothesis.

\section{OXYGEN CONSUMPTION}

Larval oxygen consumption in the present study was comparable to previously published data for larval zebrafish, following dry to wet mass conversion (Barrionuevo and Burggren, 1999; Bagatto et al., 2001). Zebrafish larvae show a significant increase in oxygen consumption during the first 8-10 days of development, most likely due to the process of organogenesis and the associated increase in metabolically active tissues. This pattern of increased mass-specific $\dot{M} \mathrm{o}_{2}$ - even as body mass is also increasing - is a pattern of metabolic change counter to that predicted by interspecific allometry, and has been previously noted in the larvae of zebrafish and other species (e.g., Barrionuevo and Burggren, 1999; Burggren, 2005; Blank and Burggren, unpublished).

Soon after the developmental peak in oxygen consumption at approximately $10 \mathrm{dpf}$, larval zebrafish are primarily using gills for gas exchange and depend heavily upon blood convection rather than bulk diffusion for oxygen transport (Pelster and Burggren, 1996). Concurrently, there is a decrease followed by stabilization of aerobic metabolism (Jonz and Nurse, 2006). In addition to the maturation of regulatory mechanisms, the reduction of massspecific oxygen consumption may also be caused by scaling-related differences due to the dramatic increase in body mass during subsequent development (Barrionuevo and Burggren, 1999). This general pattern of bipartite change in oxygen consumption during early development appears to be a general characteristic of larval teleosts (Rombough, 1988, 1998; Rombough and Ure, 1991; Barrionuevo and Burggren, 1999; Blank and Burggren, unpublished).

Routine oxygen consumption, like heart rate, differed significantly between $\mathrm{L}_{\mathrm{HSD}}$ and $\mathrm{L}_{\mathrm{LSD}}$, with the developmental trajectory for routine oxygen consumption in $\mathrm{L}_{\mathrm{LSD}}$ shifted slightly to the right in a plot of $\dot{M} \mathrm{o}_{2}$ as a function of development (Figure 3). This shift in metabolic rate could be due to the $\mathrm{L}_{\mathrm{LSD}}$ undergoing a longer period of organogenesis and its associated demand for $\dot{M} \mathrm{o}_{2}$. Alternatively, there may be a delayed conversion of egg yolk into new metabolizing biomass (Barrionuevo and Burggren, 1999). Either phenomenon could result from conventional genetic mechanisms, although epigenetic transgenerational phenomena involving physiology are increasingly being identified (e.g., Ho and Burggren, 2010; Ho et al., 2011). Irrespective of mechanism, like heart rate, the early onset of differences in oxygen consumption between larval populations shows that achievement of juvenile or adult features is not a required precondition for the expression of inherited physiological differences.

Another key determinant in oxygen consumption is the ability of the heart to supply oxygen to aerobic muscle tissue. This major factor can actually limit maximum aerobic capacity in vertebrates (e.g., Burggren et al., 1996; Hussain et al., 2001). Our results for active mass-specific oxygen consumption show a slight delay in peak oxygen consumption during development for $\mathrm{L}_{\mathrm{HSD}}$ compared to $\mathrm{L}_{\mathrm{LSD}}$. This delay could possibly be related to these particular larvae being physiologically adapted to coping with the increasing demands for oxygen delivery to the muscle tissues during activity.

\section{AEROBIC SCOPE}

Factorial aerobic scope, calculated as active aerobic metabolic rate divided by routine aerobic metabolic rate, is an important determinant of how well an animal can cope with changing environmental conditions (Brett, 1971; Killen et al., 2007). The attainable maximum level of aerobic performance in fish dictates the magnitude of the aerobic scope. Yet, for such an important indicator of physiological performance, very few data exist for larval fishes. Killen et al. (2007) suggests that marine teleost larvae have very small aerobic scopes $(\sim 1.5)$, and that physiological function is thus highly constrained. In the present study on the fresh-water zebrafish, however, larvae exhibited more substantial (and variable) aerobic scopes, ranging from values of 2 to 6 (Figure 4). By $5 \mathrm{dpf}$ there was a highly significant increase in oxygen consumption between routine and active measurements for both stamina groups, suggesting that at this early developmental stage larval zebrafish have the ability to substantially increase delivery of oxygen to muscle tissues.

There was no consistent pattern in differences in aerobic scope across the first 21 days of development or as a result of stamina grouping, and indeed some of the data are paradoxical. For example, larvae from low stamina adults actually have a much larger aerobic scope than larvae from high stamina adults at days 5 and 7 (Figure 4), whereas trained vertebrate athletes often have higher aerobic scope than untrained individuals (Weibel et al., 2004). Aerobic scope in marine teleosts is highly influenced by larval growth, developmental trajectory, and the ecological niche of the species (Killen et al., 2007; Pörtner et al., 2010). Therefore, differences in aerobic scope between stamina groups across development in this study might also relate to the differences in larval mass, length, and other as yet unidentified variables. Clearly the patterns of change during development as well as the differences between larval populations are complex and dynamic, and warrant additional study.

\section{GROSS COST OF TRANSPORT}

Gross cost of transport is used both as a measure of swimming efficiency and to compare energetic costs incurred by locomotion (e.g., Clark and Seymour, 2006). The gross cost of swimming followed a similar trend to $\dot{M} \mathrm{o}_{2}$ during the transition from larval to juvenile form, with a rapid increase during the first week of development. This pattern could arise from changes in morphological characteristics occurring during this period, such as increased body mass and size, as well as physiological adjustments such as an increase in cardio-respiratory function. As body size and surface area increase during development, so does drag during locomotion, generally leading to an increase in the energetic costs of swimming in fish (Webb, 1975). However, there also appears to be a behavioral component contributing to variability in the energetics of swimming, since fish larvae exhibit a lower cost of transport by apparently swimming more economically when in hypoxic water (Wieser, 1995).

Despite differences in body mass and length over several days of development in larval zebrafish, the cost of transport was only significantly different between larval populations at $7 \mathrm{dpf}$ (Figure 5). That gross cost of transport was elevated in the $\mathrm{L}_{\mathrm{LSD}}$ is suggestive, however, that the overall energetic efficiency of locomotion is higher in those larvae from parents with higher swimming stamina. 


\section{CONCLUSION}

This study of larval zebrafish indicates that difference in parental stamina lead to transgenerational (likely inherited) differences in cardiac and metabolic performance in larval offspring. Importantly, these differences appear early on in larval development, not requiring additional growth and development to juvenile or adult stages for the expression of traits potentially conferring greater swimming stamina. Assuming that these physiological differences between larval populations are adaptive (most likely in increased locomotor capabilities allowing both enhanced prey capture and predator avoidance), this phenomenon may convey enhanced larval fitness at a life cycle phase when selection pressures can be especially severe. The ability to successfully move to more suitable environments increases evolutionary fitness in fishes, and may depend on the locomotor capacity of the fish (Nelson et al., 2002).

Understanding the locomotory fitness of fish, and the factors that affect inheritance of this parameter, has practical implications

\section{REFERENCES}

Arnott, S. A., Susumu, C., and Conover, D. O. (2006). Evolution of intrinsic growth rate: metabolic costs drive trade-offs between growth and swimming performance in Menidia menidia. Evolution 60, 1269-1278.

Bagatto, B., and Burggren, W. W. (2001). A three-dimensional functional assessment of heart and vessel development in the larva of the zebrafish (Danio rerio). Physiol. Biochem. Zool. 79, 194-201.

Bagatto, B., Pelster, B., and Burggren, W. W. (2001). Growth and metabolism of larval zebrafish: effects of swim training. J. Exp. Biol. 204, 4335-4343.

Barrionuevo, W. R., and Burggren, W. W. (1999). $\mathrm{O}_{2}$ consumption and heart rate in developing zebrafish (Danio rerio): influence of temperature and ambient $\mathrm{O}_{2}$. Am. J. Physiol. Regul. Integr. Comp. Physiol. 276, R505-R5131.

Barrionuevo, W. R., Fernandes, M. N., and Rocha, O. (2010). Aerobic and anaerobic metabolism for the zebrafish, Danio rerio, reared under normoxic and hypoxic conditions and exposed to acute hypoxia during development. Braz. J. Biol. 70, 425-434.

Beamish, F. H. (1979). "Swimming capacity," in Fish Physiology, Vol. 7, eds S. Hoar and D. J. Randall (New York: Academic Press), 101-187.

Brett, J. R. (1971). Energetic responses of salmon to temperature. A study of some thermal relations in the physiology and freshwater ecology of sockeye salmon. Am. Zool. 11, 99-113.

Burggren, W. W. (2005). Developing animals flout prominent assumptions of ecological physiology. Comp.
Biochem. Physiol. A Mol. Integr. Physiol. 141, 430-439.

Burggren, W. W., and Bagatto, B. (2008). "Cardiovascular anatomy and physiology of larval fishes," in Fish Larval Physiology, eds N. Finn and B. G. Kapoor (New Delhi: Oxford and IBH Publishing Co. Pvt. Ltd), 119-161.

Burggren, W. W., Farrell, A. P., and Lillywhite, H. B. (1996). "Vertebrate cardiovascular systems," in Handbook of Comparative Physiology, ed. W. Dantzler (Oxford: Oxford University Press), 215-308.

Claireaux, G., and Lefrançois, C. (2007). Linking environmental variability and fish performance: integration through the concept of scope for activity. Philos. Trans. R. Soc. Lond. B Biol. Sci. 362, 2031-2041.

Claireaux, G., McKenzie, D. J., Genge, A. G., Chatelier, A., Aubin, J., and Farrell, A. P. (2005). Linking swimming performance, cardiac pumping ability and cardiac anatomy in rainbow trout. J. Exp. Biol. 208, 1175-1784.

Clark, T. D., and Farrell, A. P. (2011). Effects of body mass on physiological and anatomical parameters of mature salmon: evidence against a universal heart rate scaling exponent. J. Exp. Biol. 214, 887-893.

Clark, T. D., Jeffries, K. M., Hinch, S. G., and Farrell, A. P. (2011). Exceptional aerobic scope and cardiovascular performance of pink salmon (Oncorhynchus gorbuscha) may underlie resilience in a warming climate. J. Exp. Biol. 214, 3074-3081.

Clark, T. D., and Seymour, R. S. (2006). Cardiorespiratory physiology and swimming energetics of a highenergy-demand teleost, the yellowtail kingfish (Seriola lalandi). J. Exp. Biol. 209, 3940-3951.

for both marine and fresh-water fisheries as well as natural populations. For example, human land development is increasing the presence of culverts and dams that pose challenges to migrating fishes. Such construction results in threats to anadromous species and also changes in the use of upstream habitats (Morinville and Rasmussen, 2006).

Finally, the current study reinforces the role of the zebrafish as a suitable model system for further study of the locomotor ecology, behavior, and evolution of fishes and the transgenerational transfer of locomotor traits.

\section{ACKNOWLEDGMENTS}

This study was supported by NSF Operating Grant IOS-1025823 to Warren W. Burggren. We are grateful to Drs. Mark Burleson, Ed Dzialowski, Ione Hunt von Herbing, Pudur Jagadeswaran, and Casey Mueller for useful comments provided during the course of this study.

Colwill, R. M., and Creton, R. (2011). Locomotor behaviors in zebrafish (Danio rerio) larvae. Behav. Processes 86, 222-229.

Evans, J. P., Kelly, J. L., Bisazza, A. Finazzo, E., and Pilastro, A. (2004). Sire attractiveness influences offspring performance in guppies. Proc. Biol. Sci. 271, 2035-2042.

Farrell, A. P. (2002). Cardiorespiratory performance in salmonids during exercise at high temperature: insights into cardiovascular design limitations in fishes. Comp. Biochem. Physiol. A Mol. Integr. Physiol. 132, 797-810.

Farrell, A. P. (2007). Cardiorespiratory performance during prolonged swimming tests with salmonids: a perspective on temperature effects and potential analytical pitfalls. $\mathrm{Phi}$ los. Trans. R. Soc. Lond. B Biol. Sci. 362, 2017-2030.

Finn, R. N. (2007). The physiology and toxicology of salmonid eggs and larvae in relation to water quality criteria. Aquat. Toxicol. 81, 337-354.

Goldann, O., Popper, D., and Karpluss, I. (2003). Food competition in small groups of juvenile gilthead sea bream (Sparus aurata). Isr. J. Aquac. 55, 94-106.

Hart, P. J. B., and Salvanes, A. G. V. (2000). Individual variation in competitive performance of juvenile cod and its consequences for growth. J. Mar. Biol. Assoc. U.K. 80, 569-570.

Hastings, D., and Burggren, W. W. (1995). Developmental changes in oxygen consumption regulation in larvae of the South African clawed frog Xenopus laevis. J. Exp. Biol. 198, 2465-2475.

Ho, D., and Burggren, W. W. (2010). Epigenetics and transgenerational transfer: a physiological perspective. J. Exp. Biol. 213, 3-16.

Ho, D., Reed, W. L., and Burggren, W. W. (2011). Egg yolk environment differentially influences physiological and morphological development of broiler and layer chicken embryos. J. Exp. Biol. 214, 619-628.

Hunt von Herbing, I. (2006). “The physiological basis for metabolic scaling in animals: a developing perspective," in Comparative Developmental Physiology: Contributions, Tools and Trends, eds S. J. Warburton, W. W. Burggren, B. Pelster, C. L. Reiber, and J. Spicer (Oxford: Oxford University Press), 83-98.

Hurst, T. P., Kay, B. H., Ryan, P. A., and Brown, M. D. (2007). Sublethal effects of mosquito larvicides on swimming performance of larvivorous fish Melanotaenia duboulayi (Atheriniformes: Melanotaeniidae). J. Econ. Entomol. 100, 61-65.

Hussain, S. O., Barbato, J. C., Koch, L. G., Metting, P. J., and Britton, S. L. (2001). Cardiac function in rats selectively bred for low- and high-capacity running. Am. J. Physiol. Regul. Integr. Comp. Physiol. 281, 1787-1791.

Johnston, I. A. (2006). Environment and plasticity of myogenesis in teleost fish. J. Exp. Biol. 209, 2249-2264.

Johnston, I. A., Bower, N. I., and MacQueen, D. J. (2011). Growth and the regulation of myotomal muscle mass in teleost fish. J. Exp. Biol. 214, 1617-1628.

Jonz, M. G., and Nurse, C. A. (2006). Ontogenesis of oxygen chemoreception in aquatic vertebrates. Respir. Physiol. Neurobiol. 154, 139-152.

Killen, S. S., Costa, I., Brown, J. A., and Gamperi, A. K. (2007). Little left in the tank: metabolic scaling in 
marine teleosts and its implications for aerobic scope. Proc. Biol. Sci. 274, 431-438.

Langerhans, R. B., Layman, C. A., Shokrollahi, A. M., and DeWitt, T. J. (2004). Predator driven phenotypic diversification in Gambusia affinis. Evolution 58, 2305-2318.

Leis, J. M. (2006). Are larvae of demersal fishes plankton or nekton? Adv. Mar. Biol. 51, 57-141.

Lindsey, B. W., Smith, F. M., and Croll, R. P. (2010). From inflation to flotation: contribution of the swimbladder to whole-body density and swimming depth during development of the zebrafish (Danio rerio). Zebrafish 7, 85-96.

MacPhail, R. C., Brooks, J., Hunter, D. L., Padnos, B., Irons, T. D., and Padilla, S. (2009). Locomotion in larval zebrafish: influence of time of day, lighting and ethanol. Neurotoxicology 30, 52-58.

Martínez, M., Bédard, M., Dutil, J. D., and Guderley, H. (2004). Does condition of Atlantic cod (Gadus morhua) have a greater impact upon swimming performance at Ucrit or sprint speeds? J. Exp. Biol. 207, 979-990.

McLean, D. L., and Fetcho, J. R. (2009). Spinal interneurons differentiate sequentially from those driving the fastest swimming movements in larval zebrafish to those driving the slowest ones. J. Neurosci. 29, 13566-13577.

Morinville, G. R., and Rasmussen, J. B. (2006). Does life-history variability in salmonids affect habitat use by juveniles? A comparison among streams open and closed to anadromy. J. Anim. Ecol. 75, 693-704.

Müller, U. K., Stamhuis, E. J., and Videler, J. J. (2000). Hydrodynamics of unsteady fish swimming and the effects of body size: comparing the flow fields of fish larvae and adults. J. Exp. Biol. 203, 193-206.

Müller, U. K., van den Boogaart, J. G., and van Leeuwen, J. L. (2008). Flow patterns of larval fish: undulatory swimming in the intermediate flow regime. J. Exp. Biol. 211, 196-205.

Müller, U. K., and van Leeuwen, J. L. (2004). Swimming of larval zebrafish: ontogeny of body waves and implications for locomotory development. J. Exp. Biol. 207, 853-868.

Nelson, J. A., Gotwalt, P. S., Reidy, S. P., and Webber, D. M. (2002). Beyond $U_{\text {crit }}$ : matching swimming performance tests to the physiological ecology of the animal, including a new fish 'drag strip.'
Comp. Biochem. Physiol. A Mol. Integr. Physiol. 133, 289-302.

Nilsson, G. E., Ostlund-Nilsson, S., Penfold, R., and Grutter, A. S. (2007). From record performance to hypoxia tolerance: respiratory transition in damselfish larvae settling on a coral reef. Proc. Biol. Sci. 274, 79-85.

Pelster, B. (2002). Developmental plasticity in the cardiovascular system of fish, with special reference to the zebrafish. Comp. Biochem. Physiol. A Mol. Integr. Physiol. 133, 547-553.

Pelster, B., and Burggren, W. W. (1996). Disruption of hemoglobin oxygen transport does not impact oxygen - dependent physiological processes in developing embryos of zebrafish (Danio rerio). Circ. Res. 79, 358-362.

Pelster, B., Sänger, A. M., Siegele, M., and Schwerte, T. (2003). Influence of swim training on cardiac activity, tissue capillarization, and mitochondrial density in muscle tissue of zebrafish larvae. Am. J. Physiol. Regul. Integr. Comp. Physiol. 285, R339-R347.

Plaut, I. I., and Gordon, M. (1994). Swimming metabolism of wild-type and cloned zebrafish Brachydanio rerio. J. Exp. Biol. 194, 209-223.

Porter, M. E., Roque, C. M., and Long, J. H. Jr. (2011). Swimming fundamentals: turning performance of leopard sharks (Triakis semifasciata) is predicted by body shape and postural reconfiguration. Zoology (Jena) 114, 348-359.

Pörtner, H. O., Schulte, P. M., Wood, C. M., and Schiemer, F. (2010). Niche dimensions in fishes: an integrative view. Physiol. Biochem. Zool. 83, 808-826.

Reid, D. P., Szanto, A., Glebe, B., Danzmann, R. G., and Ferguson, M. M. (2005). QTL for body weight and condition factor in Atlantic salmon (Salmo salar): comparative analysis with rainbow trout (Oncorhynchus mykiss) and Arctic charr (Salvelinus alpinus). Heredity 94, 166-172.

Ricker, W. E. (1979). "Growth rates and models," in Fish Physiology, Vol. 8, Bioenergetics and Growth, eds W. S. Hoar, D. J. Randall, and J. R. Brett (New York: Academic Press), 677-743.

Rogge, J. R., and Warkentin, K. M. (2008). External gills and adaptive embryo behavior facilitate synchronous development and hatching plasticity under respiratory constraint. J. Exp. Biol. 211, 3627-3635.

Rombough, P. J. (1988). "Respiratory gas exchange, aerobic metabolism, and effects of hypoxia during early life," in Fish Physiology, Vol. 11, Part A, eds W. S. Hoar and D. J. Randall (San Diego, CA: Academic Press), 59-161.

Rombough, P. J. (1998). Partitioning of oxygen uptake between the gills and skin in fish larvae: a novel method for estimating cutaneous oxygen uptake. J. Exp. Biol. 201, 1763-1769.

Rombough, P. J. (2006). “Developmental costs and the partition of metabolic energy," in Comparative Devel opmental Physiology: Contributions, Tools and Trends, eds S. J. Warburton, W. W. Burggren, B. Pelster, C. L. Reiber, and J. Spicer (Oxford: Oxford University Press), 99-123.

Rombough, P. J., and Ure, D. (1991). Partitioning of oxygen uptake between cutaneous and branchial surfaces in larval and juvenile chinook salmon Oncorhynchus tshawytscha. Physiol. Zool. 64, 717-727.

Sandblom, E., Farrell, A. P., Altimiras, J., Axelsson, M., and Claireaux, G. (2005). Cardiac preload and venous return in swimming sea bass (Dicentrarchus labrax L.). J. Exp. Biol. 208 1927-1935.

Schwerte, T., Prem, C., Mairösl, A., and Pelster, B. (2006). Development of the sympatho-vagal balance in the cardiovascular system in zebrafish (Danio rerio) characterized by power spectrum and classical signal analysis. J. Exp. Biol. 209, 1093-1100.

Schwerte, T., Voigt, S., and Pelster, B. (2005). Epigenetic variations in early cardiovascular performance and hematopoiesis can be explained by maternal and clutch effects in developing zebrafish (Danio rerio). Comp. Biochem. Physiol. A Mol. Integr. Physiol. 141, 200-209.

Steele, S. L., Yang, X., Debiais-Thibaud, M., Schwerte, T., Pelster, B., Ekker, M., Tiberi, M., and Perry, S. F. (2011). In vivo and in vitro assessment of cardiac beta-adrenergic receptors in larval zebrafish (Danio rerio). J. Exp. Biol. 214, 1445-1457.

Territo, P., and Burggren, W. W. (1998). Cardio-respiratory ontogeny during chronic carbon monoxide induced hypoxemia in the clawed frog Xenopus laevis. J. Exp. Biol. 201, 1461-1472.

Thorsen, D. H., Cassidy, J. J., and Hale, M. E. (2004). Swimming of larval zebrafish: fin-axis coordination and implications for function and neural control. J. Exp. Biol. 207, 4175-4183.

Tierney, K. B., Patterson, D. A., and Kennedy, C. J. (2009). The influence of maternal condition on offspring performance in sockeye salmon Oncorhynchus nerka. J. Fish Biol. 75, 1244-1257.

van der Meulen, T., Schipper, H., van den Boogaart, J. G., Huising, M. O., Kranenbarg, S., and van Leeuwen, J. L. (2006). Endurance exercise differentially stimulates heart and axial muscle development in zebrafish (Danio rerio). Am. J. Physiol. Regul. Integr. Comp. Physiol. 291, R1040R1048.

Wark, A. R., Greenwood, A. K., Taylor, E. M., Yoshida, K., and Peichel, C. L. (2011). Heritable differences in schooling behavior among threespine stickleback populations revealed by a novel assay. PLoS ONE 6, e18316. doi:10.1371/journal.pone. 0018316

Webb, P. W. (1975). Hydrodynamics and Energetics of Fish Propulsion. Department of the Environment Fisheries and Marine Service, 190.

Webber, D. M., Boutilier, R. G., and Kerr, S. R. (1998). Cardiac output as a predictor of metabolic rate in cod Gadus morhua. J. Exp. Biol. 201, 2779-2789.

Weibel, E. R., Bacigalupe, L. D., Schmitt, B., and Hoppeler, H. (2004). Allometric scaling of maximal metabolic rate in mammals: muscle aerobic capacity as determinant factor. Respir. Physiol. Neurobiol. 140, 115-132.

Wieser, W. (1995). Energetics of fish larvae, the smallest vertebrates. Acta Physiol. Scand. 154, 279-290.

Conflict of Interest Statement: The authors declare that the research was conducted in the absence of any commercial or financial relationships that could be construed as a potential conflict of interest.

Received: 10 November 2011; accepted: 07 February 2012; published online: 24 February 2012.

Citation: Gore $M$ and Burggren WW (2012) Cardiac and metabolic physiology of early larval zebrafish (Danio rerio) reflects parental swimming stamina. Front. Physio. 3:35. doi: 10.3389/fphys.2012.00035

This article was submitted to Frontiers in Aquatic Physiology, a specialty of Frontiers in Physiology.

Copyright (c) 2012 Gore and Burggren. This is an open-access article distributed under the terms of the Creative Commons Attribution Non Commercial License, which permits non-commercial use, distribution, and reproduction in other forums, provided the original authors and source are credited. 